\title{
Gas Chromatographic Determination of the Absolute Configuration of Secondary Alcohols and Ketones Having 7-Carboxybicyclo- [2.2.1]heptane Skeleton
}

\author{
Yoshimitsu YamazaKi and Hidekatsu MaEDA \\ Fermentation Research Institute, Agency of Industrial Science and Technology, \\ Ministry of International Trade and Industry, \\ Yatabe-machi Higashi-1-1-3, Tsukuba, \\ Ibaraki 305, Japan \\ Received June 11, 1985
}

\begin{abstract}
Stereoisomers of 7-carboxy- and/or 7-methoxycarbonylbicyclo[2.2.1]heptan-2-ol, heptan-2one, hept-5-en-2-ol, and hept-5-en-2-one were prepared as the racemic and enantiomerically pure forms. Gas chromatographic enantiomer separation of these compounds was investigated for their diastereomeric derivatives prepared with eight chiral reagents. Among them, $(R)-(-)-1-$ (1-naphthyl)ethyl isocyanate and $(R)-(+)-\alpha$-methylbenzylamine were the most effective reagents for the hydroxy esters and keto acids, respectively, from the point of complete resolution of the enantiomers on OV-1 capillary columns. The peak components were assigned including the absolute configuration.
\end{abstract}

Chiral 2-hydroxy- or 2-oxobicyclo[2.2.1]heptane-7-carboxylic acid, hept-5-ene-7-carboxylic acid, and their methyl esters are potentially useful synthons for optically active cyclopentanoids such as (-)-methyl jasmonate and natural prostaglandins. ${ }^{1)}$ We have reported that the chiral hydroxy compounds were produced by the stereoselective microbiological hydroxylation of the prochiral precursors, 7-carboxy- or 7-methoxycarbonylbicyclo[2.2.1]heptane (1) and heptene (2), and in some cases the chiral oxo compounds were produced by the succeeding biological oxidation. ${ }^{1)}$

The problem we encountered in the screening of microorganisms was to determine the absolute configuration and enantiomeric purity of the microbial products, as simply as possible and with a small amount of the sample, for convenience in rapid screening. The following methods can be applied to small-scale determination of absolute configuration, if at least one optically active specimen of known absolute configuration is available as a standard for each compound: (1) NMR measurements; ${ }^{2)}$ (2) chromatographic resolution on chiral stationary phases; ${ }^{3 a, b)}$ and (3) chromatography on achiral stationary phases, but for diastereomeric derivatives of the sample with a chiral derivatizing reagent. ${ }^{3 \mathrm{~b}, \mathrm{c})}$ The NMR methods require relatively pure samples and the chiral phases for gas and highperformance liquid chromatography are usually hard to obtain. In method 3 coupled with gas chromatography, the amount of sample required is very small $(<0.1 \mathrm{mg})$, purification of the sample is usually unnecessary, and various columns or stationary phases are easily available. This method with gas chromatography was used in our previous work ${ }^{1)}$ to study the stereochemistry of microbial products. In this paper, we report details of the synthesis of authentic specimens, derivatization of these specimens to diastereomers with various chiral reagents, and gas chromatographic separation of these diastereomers.

The microbial products were the stereoisomers of the hydroxy or keto acids and methyl esters (3 11). Among them, some compounds $\left(( \pm)-\mathbf{3 a},,^{4)} \quad( \pm)-\mathbf{4 a}, \mathbf{b},{ }^{4,5)} \quad( \pm)\right.$ 
$\mathbf{5 a}, \mathbf{b}^{4,5,6)}( \pm)-\mathbf{6} \mathbf{b},{ }^{4)}( \pm)-7 \mathbf{a}, \mathbf{b}^{4,7)}(+)-7 \mathbf{a}^{8 \mathbf{a})}$ $( \pm)-8 \mathbf{a}, b^{4)},{ }^{4)}(+)-8 \mathbf{b}^{8 b}$ and $(-)-8 b^{8 a)}$ and $( \pm)-$ $\left.\mathbf{1 1}^{9)}\right)$ have been reported earlier, but others including the necessary key compounds, $(1 R)-$ and/or $(1 S)-5$ and $\mathbf{1 1}$, were not found in the literature. Thus, racemic and chiral specimens for these compounds were prepared in a stereocontrolled way from a common precursor, tricyclo keto acid $\mathbf{1 2}$.
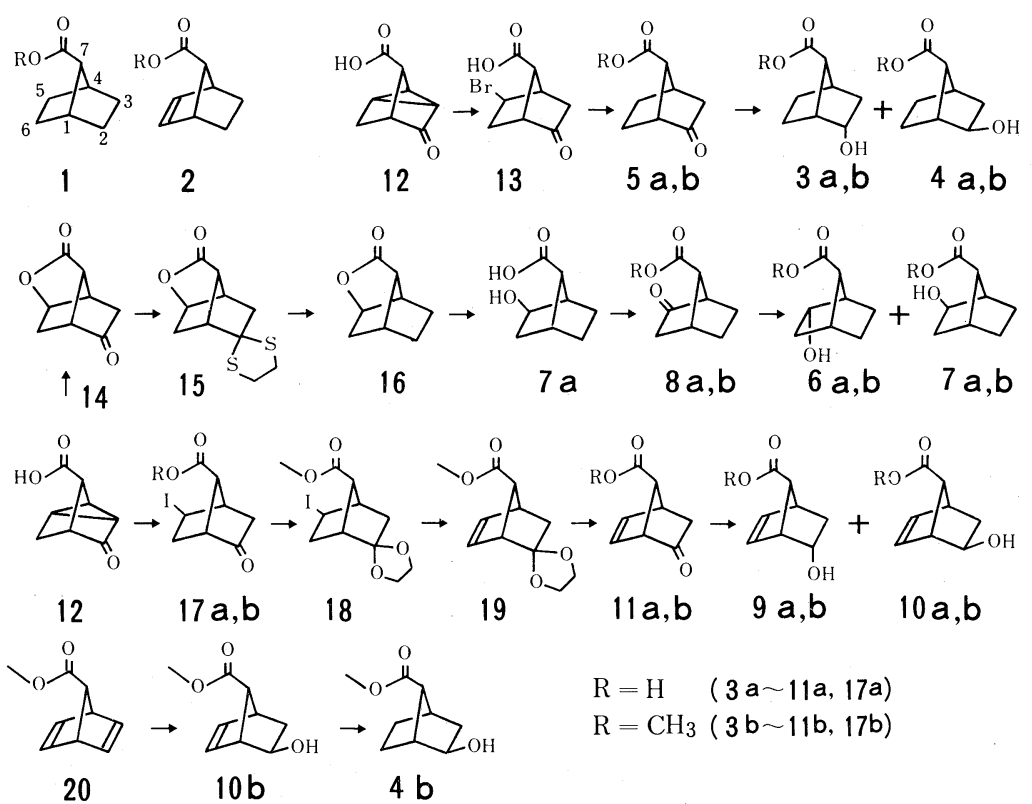

$11 a, b \quad 9 a, b \quad 10 a, b$

$\mathrm{R}=\mathrm{H} \quad(3 \mathrm{a} \sim 11 \mathrm{a}, 17 \mathrm{a})$

$\mathrm{R}=\mathrm{CH}_{3}(3 \mathrm{~b} \sim 11 \mathrm{~b}, 17 \mathrm{~b})$

Addition of hydrobromic acid to the cyclopropane ring of $\mathbf{1 2}$ gave the syn bromo keto acid 13, as reported by Beeley et al. ${ }^{6)}$ The bromide was reduced with zinc powder to yield the anti keto acid 5a. The dextrorotatory tricyclo acid $(+)-\mathbf{1 2}$ was similarly converted to the optically active keto acid $(+)$ 5a. The dextrorotatory acid $(+)-\mathbf{1 2}$ was the synthetic precursor for natural prostaglandins. ${ }^{9)}$ The absolute configuration of $(+)$ 5a is, therefore, $1 R, 4 R$ and $7 R$. The keto acid 5a was methylated with diazomethane to the keto ester $\mathbf{5 b}$, which was reduced with sodium borohydride in isopropyl alcohol to give a mixture of the endo anti hydroxy ester $\mathbf{3 b}$ and exo anti hydroxy ester $\mathbf{4 b}$ in $\mathbf{a}$ ratio of $9: 1$. The ratio was estimated by gas chromatography and the endo and exo assignment was made by comparing the retention time of the peaks with that of another stereoselectively synthesized $\mathbf{4 b}$ (see below) under the same gas chromatographic conditions.
The predominancy of endo hydroxy configuration in the sodium borohydride reduction has also been reported for other bicyclo[2.2.1]heptanes. ${ }^{10)}$ Chiral specimens for $\mathbf{3 b}$ and $\mathbf{4 b}$ were prepared from $(1 R)-(+)-5 \mathbf{a}$ and $(1 S)-(-)-5 \mathbf{a}$. The latter acid was obtained from (-)-12.

The racemic syn keto acid $\mathbf{8 a}$ was also synthesized from 12. Treatment of $\mathbf{1 2}$ with sulfuric acid according to the method of Bindra et al. ${ }^{9)}$ yielded the keto lactone 14, which was converted to the dithioketal lactone 15. The dithioketal group was removed by reduction with Raney Ni. The resulting lactone 16 was hydrolyzed and oxidized with Jones reagent to give the $s y n$ keto acid $8 \mathbf{a}$. The dextrorotatory tricyclo keto acid (+)-12 was similarly converted to the optically active $s y n$ keto acid (+)-8a, leading to the $1 R$ absolute configuration of $(+)-\mathbf{8 a}$. Optically active $\mathbf{8 a}$ and its methyl ester were also synthesized by Nakazaki et al., ${ }^{8)}$ but by using bicyclo- 
[2.2.1]hept-5-ene-2-endo-carboxylic acid as the starting material. Unfortunately, optical rotation for the acid has not been reported in the literature. Methylation and sodium borohydride reduction of $\mathbf{8 a}$ (for both the racemic and optically active specimen) gave a mixture of the endo syn hydroxy ester $\mathbf{6 b}$ and exo syn hydroxy ester $7 \mathbf{b}$ in a ratio of $4: 1$. The minor product $\mathbf{7 b}$ was identical in gas chromatography-mass spectrometry to another specimen of $\mathbf{7 b}$ obtained from the hydrolyzate of $\mathbf{1 6 .}$

The unsaturated compounds 9 11 were also synthesized from the tricyclo keto acid $\mathbf{1 2}$. Addition of hydroiodic acid to $\mathbf{1 2}$ gave the iodo keto acid $\mathbf{1 7 a},{ }^{6)}$ which was converted to the methyl ester $\mathbf{1 7 b}$ with diazomethane. The keto group of $\mathbf{1 7 b}$ was protected as ethylene ketal. The iodo ketal ester $\mathbf{1 8}$ was treated with a base, 1,8-diazabicyclo[5.4.0]undec-7-ene, to afford the unsaturated ester ketal 19. The protective groups in $\mathbf{1 9}$ were removed with an acid and base, respectively. The product, unsaturated keto acid 11a, was purified by crystallization. Then, the acid was again methylated and reduced with sodium borohydride to give a mixture of the endo hydroxy ester $9 \mathrm{~b}$ and exo hydroxy ester $\mathbf{1 0 b}$ in a ratio of $92: 8$. In the same way, the dextrorotatory tricyclo keto acid $(+)-12$ was converted to the optically active unsaturated keto acid (-)-11a. This levorotatory acid (-)-11a was assigned $1 R$ as the absolute configuration for the same reason as mentioned for $(1 R)-(+)-5 a$. Methylation and sodium borohydride reduction of $(1 R)-(-)-11$ a gave a mixture of $(1 R)-9 \mathbf{b}$ and (1R)-10b.

The exo hydroxy configuration of the minor product (10b) in the borohydride reduction of 11b was confirmed by the fact that retention time and mass spectrum for the specimen of 10b in gas chromatography-mass spectrometry were identical to those for another specimen of 10b, which was obtained by the exo-selective hydroboration of a 7-substituted diene ester (20) with 9-borabicyclo[3.3.1]nonane. The reagent has been reported to form predominantly an exo anti alcohol from a 7-sub- stituted norbornadiene. ${ }^{11)}$ Catalytic hydrogenation of $\mathbf{1 0 b}$ gave $\mathbf{4 b}$.

Gas chromatographic enantiomer separation of chiral alcohols and acids as their diastereomeric derivatives is an important analytical method for determining the absolute configuration and enantiomeric (optical) purity of the chiral compounds. ${ }^{3 a, c)}$ The method has been widely studied for many kinds of substrates using various chiral derivatizing reagents such as (-)-menthyl chloroformate $\left(\right.$ 21) ${ }^{12)} \quad N$-trifluoroacetyl-( $\left.S\right)$-prolyl chloride $(22),{ }^{13)}(R)-(+)-\alpha$-methoxy- $\alpha$-trifluoromethylphenylacetic acid chloride $\left.(23),{ }^{14}\right)(R)-(+)$ $\alpha$-methylbenzyl isocyanate $(\mathbf{2 4}),{ }^{15)}$ and $(R)$ $(+)$-trans-chrysanthemoyl chloride,$^{13,16,17)}$ for alcohols; and chiral alcohols (e.g., (-)menthol ${ }^{18)}$ ) and chiral amines (e.g., amino acid derivatives ${ }^{3 \mathrm{c})}$ and $(R)-(+)-\alpha$-methylbenzylamine $(\mathbf{2 5})^{19)}$ ) for acids. Earlier studies on the substrates of bicyclo[2.2.1]heptane skeleton have been done with trimethyl derivatives such as borneol, ${ }^{16}$ ) isoborneol, ${ }^{16)}$ camphor $^{20)}$ and fenchol. ${ }^{16)}$ No work has been reported on a simpler unsubstituted or only monosubstituted norbornane derivative. Thus six species of diastereomeric deriva-

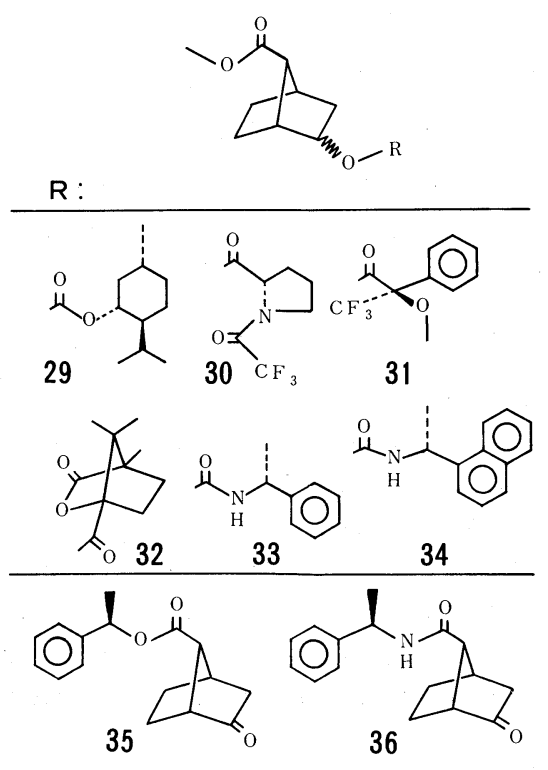

tives $(\mathbf{2 9}, \mathbf{3 0}, \mathbf{3 1}, \mathbf{3 2}, 33$ and 34$)$ were prepared by treating the present anti hydroxy 
esters (as the mixture of $\mathbf{3 b}$ and $\mathbf{4 b}$ ) with commercially available reagents $21,22, \mathbf{2 3}$, (-)-camphanic acid chloride (26), 24 and $(R)-(-)-1-(1-$ naphthyl)ethyl isocyanate (27), respectively. Also two species of derivatives (35 and 36) of the keto acid 5a were prepared using $(R)-(+)$-1-phenylethanol (28) and the chiral amine 25 , respectively.

Most of the diastereomeric derivatives of $\mathbf{3 b}+\mathbf{4 b}$ were separated on a capillary column (OV-1, 25 m), usually showing two pairs of peaks in each chromatogram (Fig. 1). It is reasonable to consider that the two (or one) smaller peak(s) of shorter retention time (35 55 min) represent the diastereomers of the minor component, exo alcohol $\mathbf{4 b}$, and the two larger peaks of longer retention time represent those of the major component, endo alcohol 3b. Gas chromatography-mass spectrometry using the same column as above showed that all the larger peaks and some of the smaller peaks yielded the molecular ion and/or the ion of $\mathrm{M}^{+}-31(\mathrm{OMe})$ expected for each derivative. The chromatograms in Fig. 1 were obtained in the conditions where the diastereomeric peaks were separated as far as possible within a practical retention time ( $<60 \mathrm{~min})$. Thus, as is seen from Fig. 1, the gas chromatographic enantiomer separation of the exo alcohol $\mathbf{4 b}$ was easily achieved by the derivatization with the chiral reagents except for 23 (Fig. 1c). On the other hand, resolution of the endo alcohol $\mathbf{3 b}$ was satisfactorily achieved only when derivatized with 27 (Fig. 1f).

Gas chromatographic separation of all derivatives was further tested on more polar stationary phases (OV-1701 and BP-20). A substantial improvement was found for the derivative with 26 with an OV-1701 capillary column, ${ }^{* 1}$ where the diastereomers of the endo anti alcohol $\mathbf{3 b}$ were completely separated. However, when diastereomeric derivatives of the syn alcohols $(\mathbf{6 b}+\mathbf{7 b})$ with 26 were sub-

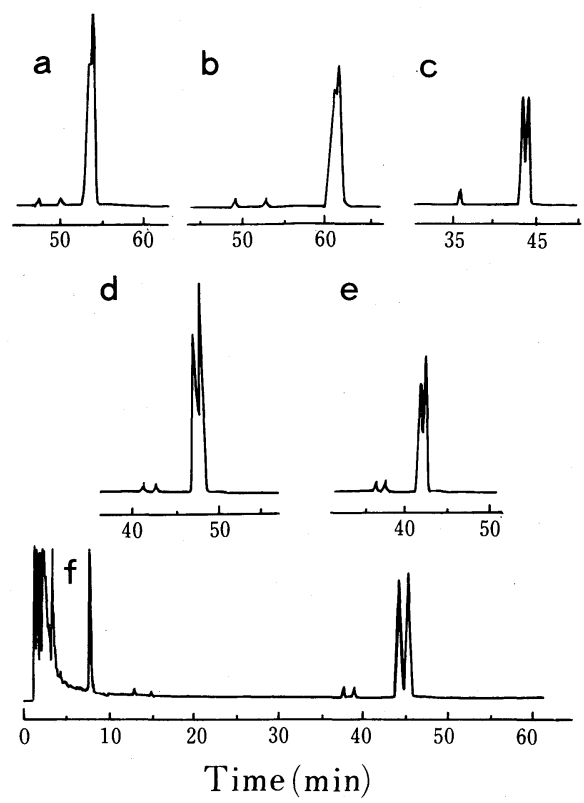

FIG. 1. Gas Chromatograms for the Diastereomeric Derivatives of the anti Hydroxy Esters $(\mathbf{3 b}+\mathbf{4 b})$ with $(-)$ Menthyl Chloroformate (a), $N$-Trifluoroacetyl- $(S)$-prolyl Chloride (b), (R)- $(+)-\alpha$-Methoxy- $\alpha$-trifluoromethylphenylacetic Acid Chloride (c), (-)-Camphanic Acid Chloride (d), $(R)-(+)-\alpha$-Methylbenzyl Isocyanate (e) and $(R)-(-)-1-(1-N a p h t h y l) e t h y l$ Isocyanate (f)

Chromatographic conditions: column, OV-1 capillary $(25 \mathrm{~m})$; inlet pressure and carrier flow rate, $1.25 \mathrm{~kg} / \mathrm{cm}^{2}$ and $75 \mathrm{ml} / \mathrm{min}$; column temperature $\left({ }^{\circ} \mathrm{C}\right)$ and flow rate in column (ml/min), 180 and 1.0 (a), 160 and $1.2(\mathrm{~b}), 170$ and 1.1 (c), 190 and 1.0 (d and e), and 230 and 0.83 (f). Relative retention time of the exo and endo diastereomers: a, 1.052 and $1.009 ; \mathrm{b}, 1.068$ and $1.009 ; \mathrm{c}, 1.0$ and $1.013 ; \mathrm{d}, 1.041$ and 1.017; e, 1.025 and 1.015; f, 1.032 and 1.022 .

jected to this column, one peak (for one diastereomer of $\mathbf{6 b}$ ) was observed to overlap with the peak for one diastereomer of $\mathbf{4 b}$. This overlap could not be avoided either by changing the column temperature or by using a BP20 column. Such an overlap did not occur in the chromatography for the derivatives with 27 on the OV-1 column. ${ }^{* 2}$ Therefore, we decided to use the chiral isocyanate 27 for derivatizing the present hydroxy esters for the gas chromatographic determination of the ab-

*1 Data of retention time are given in EXPERIMENTAL. Chromatograms are available on request.

*2 Peaks for the diastereomeric urethanes of $(1 R)-\mathbf{7 b}$ and $(1 S)-\mathbf{4 b}$ overlapped each other on the column (OV-1, $50 \mathrm{~m}$ ) used in the screening work, but the overlap was not a serious problem. ${ }^{1)}$ 


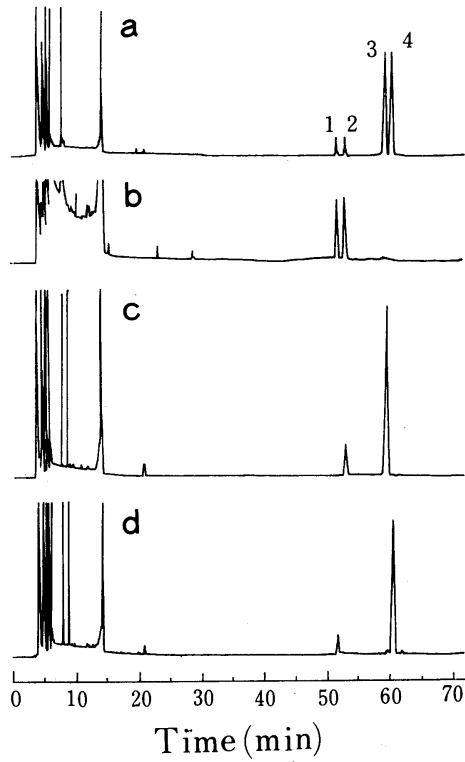

FIG. 2. Gas Chromatograms for the Diastereomeric Derivatives of the Racemic and Enantiomerically Pure Hydroxy Esters with $(R)-(-)-1-(1-N a p h t h y l) e t h y l$ Isocyanate.

Samples (hydroxy esters): $\mathbf{a},( \pm)-\mathbf{3 b}+( \pm)-\mathbf{4 b} ; \mathbf{b},( \pm)-\mathbf{4 b}$; c, $(1 R)-\mathbf{3 b}+(1 R)-\mathbf{4 b} ; \mathrm{d},(1 S)-\mathbf{3 b}+(1 S)-\mathbf{4 b}$. Chromatographic conditions: column, OV-1 capillary $(50 \mathrm{~m})$; inlet pressure and carrier flow rate, $1.75 \mathrm{~kg} / \mathrm{cm}^{2}$ and $105 \mathrm{ml} /$ min; column temperature and flow rate in column, $250^{\circ} \mathrm{C}$ and $0.54 \mathrm{ml} / \mathrm{min}$. Peak assignments, see the text.

solute stereochemistry.

Figure 2 shows the gas chromatograms with a 50-m OV-1 capillary column for the diastereomeric $(R)-1-(1-n a p h t h y l) e t h y l$ urethanes of the racemic and enantiomerically pure anti hydroxy esters. Comparison of Fig. 2a (for the diastereomers of racemic $\mathbf{3 b}$ and $\mathbf{4 b}$ ) with Fig. $2 b$ (for the diastereomers of racemic $\mathbf{4 b}$ prepared by hydroboration) confirms that the pair of smaller peaks of equal height (numbered 1 and 2) represents the diastereomers of the exo alcohol $\mathbf{4 b}$ and consequently that the pair of larger peaks of equal height (numbered 3 and 4) represents those of the endo alcohol 3b. The absolute configuration of each peak component was determined by comparing Fig. 2a with Figs. 2c and 2d, which are the chromatograms for the diastereomers of the $1 R$ and $1 S$ specimens, respectively. Thus, the peaks $1,2,3$ and 4 represent the $(1 S)$ - anti exo, (1 $R)$-anti-exo, ( $1 R)$-anti endo and (1S)-anti endo isomers, respectively. Diastereomeric derivatives of the syn hydroxy esters (6b and 7b) with 27 and those of the unsaturated hydroxy esters (9b and 10b) with the same reagent also exhibited good separation between the members of the diastereomeric pair by gas chromatography (chromatograms not shown). ${ }^{* 1}$ The peaks were assigned as described in EXPERIMENTAL, by comparing the chromatograms with those for the corresponding pure exo and pure $1 R$ specimens. The reagent, $(R)-(-)-1-(1-n a p h-$ thyl)ethyl isocyanate (27), was developed for resolution by high-performance liquid chromatography. ${ }^{3 \mathrm{~b})}$ This paper is the first to report application of this reagent to gas chromatography.

Diastereomeric esters of the keto acid 5a with 28 were little separated by gas chromatography with the $25-\mathrm{m}$ capillary column, but amides with $(R)-(+)$ - $\alpha$-methylbenzylamine (25) were well resolved. ${ }^{* 1}$ Diastereomeric amides of the syn keto acid 8a and the unsaturated keto acid 11a with this chiral amine were also completely resolved by gas chromatography. ${ }^{* 1}$ The absolute configuration of each peak component was determined using the amides of the optically active specimens.

In conclusion, the method has been established to determine the absolute stereochemistry of secondary alcohols and ketones with a 7-carboxybicyclo[2.2.1]heptane skeleton by gas chromatography. This method (for alcohols) is being applied in our screening, ${ }^{1)}$ where crude extracts from fermentation broth containing $0.1 \sim 0.2 \mathrm{mg}$ of the hydroxylated products are generally enough to be tested for the absolute configuration and enantiomeric purity of the products and all the procedures including gas chromatography can be completed within $24 \mathrm{hr}$. The present work will also provide useful information for the method of enantiomer separation by gas chromatography. 


\section{EXPERIMENTAL}

Materials. The following reagents were purchased from commercial suppliers: 9-borabicyclo[3.3.1]nonane, $(S)$ $(-)$ and $(R)-(+)-\alpha$-methylbenzylamine, $\quad(R)-(+)-\alpha-$ methylbenzyl isocyanate, and $(R)-(-)-1-(1-$ naphthyl)ethyl isocyanate, from Aldrich Chemical Co. (Milwaukee); (-)camphanic acid chloride, from Fluka AG, Chemische Fabrik (Buchs, Switzerland); (-)-menthyl chloroformate/toluene and $N$-trifluoroacetyl-(S)-prolyl chloride/ $\mathrm{CHCl}_{3}$, from Regis Chemical Co. (Chicago); $(R)-(+)-\alpha-$ methoxy- $\alpha$-trifluoromethylphenylacetic acid and TLC glass plates coated with silica gel $\mathrm{F}_{254}(0.25 \mathrm{~mm}$ thick), from Merck Japan Ltd. (Tokyo); 1,8-diazabicyclo[5.4.0]undec-7-ene and silica gel (Wako gel C-200) for column chromatography, from Wako Pure Chemical Co. (Tokyo); 7-chloronorbornadiene, from Frinton Laboratories .(Vineland, U.S.A.); and $(R)-(+)-1$-phenylethanol, from Tokyo Chemical Industry Co., Ltd. (Tokyo). All other reagents were of the best grade commercially available.

Analysis. Melting points were measured in sealed capillaries on a hot stage and are uncorrected. Optical rotations were measured with a Union Giken PM-101 automatic polarimeter or an Atago Polax polarimeter. IR, PMR and MS spectra were taken with a Jasco IRA-1 infrared spectrometer, a JEOL GX-270 NMR spectrometer and a JEOL JMS-D300 mass spectrometer equipped with a gas chromatograph, respectively. Gas chromatography (GC) was carried out with Shimadzu GC-7A, GC-R1A and GC9A gas chromatographs equipped with flame ionization detectors and data processors. When capillary columns were used, an inlet splitter (Gasukuro Kogyo) was attached to the chromatograph. Packing materials and capillary columns were obtained from Gasukuro Kogyo Inc. (Tokyo). Chromatographic conditions for packed columns were as follows: condition 1-with a glass column $(3 \mathrm{~mm}$ i.d. $\times 1.5 \mathrm{~m}$ ) packed with $5 \%$ SILAR-5CP on chromosorb W AW ( $80 \sim 100$ mesh $)$ at a carrier $\left(\mathrm{N}_{2}\right)$ flow rate of $60 \mathrm{ml} / \mathrm{min}$ and a column temperature of $160^{\circ} \mathrm{C}$; condition 2 -similar to condition 1, except for the column diameter ( $2 \mathrm{~mm}$ i.d.), carrier $(\mathrm{He})$ flow rate $(15 \mathrm{ml} / \mathrm{min})$ and column temperature $\left(145^{\circ} \mathrm{C}\right)$; condition 3 -with a glass column $(2 \mathrm{~mm}$ i.d. $\times 1.5 \mathrm{~m})$ packed with $5 \% \mathrm{SP}-1000$ on the same support as already mentioned at a He carrier flow rate of $18 \mathrm{ml} / \mathrm{min}$ and a column temperature of $170^{\circ} \mathrm{C}$. Conditions for GC with capillary columns (silica capillaries with chemically bonded stationary phases of OV-1 $(0.25 \mathrm{~mm}$ i.d. $\times 25$ and $50 \mathrm{~m})$, OV-1701 $(0.25 \mathrm{~mm}$ i.d. $\times 25 \mathrm{~m})$ and BP-20 $(0.22 \mathrm{~mm}$ i.d. $\times 25 \mathrm{~m}))$ are given in the latter section and the legends to Figs. 1 and 2. Helium was used as the carrier gas for all capillary columns. In the following sections, $t_{R}$ represents retention time ( $\mathrm{min}$ ). Gas chromatography-mass spectrometry (GC-MS) was carried out under GC condition 2, unless otherwise stated.

\section{Synthesis}

5-Oxotricyclo[2.2.1.0 $0^{2,6}$ ]heptane-3-carboxylic acid (12). The racemic acid ( \pm )-12 was prepared from norbornadiene according to Beeley et al., ${ }^{6)} \mathrm{mp} 143 \sim 144^{\circ} \mathrm{C}$ (lit. ${ }^{6}$ ) $\left.\mathrm{mp} 143 \sim 146^{\circ} \mathrm{C}\right)$. The racemic acid $( \pm)-12$ was resolved by fractional crystallization of the salts with $(-)$ - or $(+)-\alpha-$ methylbenzylamine to give the dextrorotatory acid $(+)-12$ (mp $142 \sim 143^{\circ} \mathrm{C},[\alpha]_{\mathrm{D}}^{23}+91.7^{\circ}\left(c=1.0\right.$, dioxane); lit. ${ }^{21)} \mathrm{mp}$ $142.5 \sim 143.5^{\circ} \mathrm{C},[\alpha]_{\mathrm{D}}+81.8^{\circ}(c=1$, dioxane $\left.)\right)$ and levorotatory acid (-)-12 (mp $140 \sim 142.5^{\circ} \mathrm{C},[\alpha]_{\mathrm{D}}^{24}-86.0^{\circ}$ ( $c=1.0$, dioxane). Anal. Found: C, 63.12; H, 5.31. Calcd. for $\mathrm{C}_{8} \mathrm{H}_{8} \mathrm{O}_{3}: \mathrm{C}, 63.15 ; \mathrm{H}, 5.30 \%$ ).

2-Oxobicyclo[2.2.1]heptane-7-anti-carboxylic acid (5a) was prepared from 12 by the method of Beeley et al. ${ }^{6)}$ in $93 \%$ yield, $\mathrm{mp} 103 \sim 105^{\circ} \mathrm{C}$ (lit. ${ }^{6)} \mathrm{mp} 104 \sim 106^{\circ} \mathrm{C}$ ). The optically active acids $(+)-5 \mathbf{a}$ and $(-)-5 \mathbf{a}$ were similarly prepared from $(+)-12$ and (-)-12, respectively. (+)-5a: yield, $45 \%$; mp $141 \sim 142.5^{\circ} \mathrm{C},[\alpha]_{\mathrm{D}}^{25}+18^{\circ}(c=0.87, \mathrm{MeOH})$. Anal. Found: $\mathrm{C}$, $62.30 ; \mathrm{H}, 6.56$. Calcd. for $\mathrm{C}_{8} \mathrm{H}_{10} \mathrm{O}_{3}: \mathrm{C}, 62.33 ; \mathrm{H}, 6.54 \%$. (-)5a:yield, $62 \%$; mp $140 \sim 142^{\circ} \mathrm{C},[\alpha]_{\mathrm{D}}^{25}-18^{\circ}(c=0.83, \mathrm{MeOH})$. Anal. Found: C, 62.38; $\mathrm{H}, 6.50$. Calcd. for $\mathrm{C}_{8} \mathrm{H}_{10} \mathrm{O}_{3}: \mathrm{C}, 62.33$; $\mathrm{H}, 6.54 \%$.

2-Endo-hydroxy- (3b) and 2-exo-hydroxybicyclo[2.2.1] heptane-7-anti-carboxylic acid methyl ester (4b). One milligram of $\mathbf{5 a}$ was methylated with an excess amount of ethereal diazomethane. The solvent was changed to $0.1 \mathrm{ml}$ isopropyl alcohol. To the solution was added about $1 \mathrm{mg}$ of sodium borohydride. The mixture was allowed to stand at room temperature for $1 \mathrm{hr}$ and then diluted with water $(0.1 \mathrm{ml})$. After acidification with $2 \mathrm{~N} \mathrm{HCl}$ and saturation with $\mathrm{NaCl}$, the product was extracted with ether $(0.5 \mathrm{ml} \times 2)$. The extracts were worked up in the usual way*3 and then dissolved in $0.1 \mathrm{ml}$ EtOAc. GC analysis (condition 1) for the EtOAc solution showed that the starting material $\left(t_{R}=4.73\right.$ for $\left.5 \mathrm{~b}\right)$ had been completely converted to two hydroxy esters $\mathbf{3 b}$ $\left(t_{R}=6.70\right)$ and $4 \mathbf{b}\left(t_{R}=6.00\right)$ in a ratio of $9: 1$. GC-MS $m / z$ : $170\left(\mathrm{M}^{+}\right)$for $3 \mathbf{b}\left(t_{R}=18.2\right)$ and $m / z: 170\left(\mathrm{M}^{+}\right)$for $4 \mathbf{b}$ $\left(t_{R}=16.0\right)$. In the same way, $(1 R)-(+)-5 \mathbf{a}$ and $(1 S)-(-)-5 \mathbf{a}$ were converted to a mixture of $(1 R)-\mathbf{3 b}$ and $(1 R)-\mathbf{4 b}$ and a mixture of $(1 S)-3 \mathbf{b}$ and $(1 S)-\mathbf{4 b}$, respectively.

Keto lactone 14 was prepared from 12 by the method of Bindra et al., ${ }^{9)}$ in $46 \%$ yield, mp $193 \sim 194^{\circ} \mathrm{C}$ (lit. ${ }^{9)} \mathrm{mp}$ $\left.195 \sim 196^{\circ} \mathrm{C}\right)$. Similarly, $(+)-14$ was obtained from $(+)-12$ in $45 \%$ yield, mp $195 \sim 196^{\circ} \mathrm{C},[\alpha]_{\mathrm{D}}^{24}+231^{\circ}(c=0.31$, $\mathrm{MeOH})$ (lit, $\left.{ }^{9)} \mathrm{mp} 195 \sim 197^{\circ} \mathrm{C},[\alpha]_{\mathrm{D}}+266^{\circ}(c=1, \mathrm{MeOH})\right)$, MS $m / z: 152\left(\mathbf{M}^{+}\right)$.

Dithioketal lactone (15). The keto lactone $( \pm)-14$ $(180 \mathrm{mg})$ was mixed with $0.5 \mathrm{ml}$ of ethanedithiol and $0.5 \mathrm{ml}$ of $47 \% \mathrm{BF}_{3}$ etherate. The mixture was allowed to stand at room temperature for $30 \mathrm{~min}$. After addition of $10 \mathrm{ml}$ $\mathrm{MeOH}$, the mixture was concentrated by an evaporator to give a syrup, which was crystallized from $\mathrm{MeOH}$ as plates

*3 Washed with saturated brine, dried over $\mathrm{Na}_{2} \mathrm{SO}_{4}$, and concentrated under vacuum or evaporated to dryness. 
$(70 \mathrm{mg})$. A remaining portion of the product in the mother liquor was isolated by column chromatography (silica gel, $1.5 \times 15 \mathrm{~cm}$, EtOAc/benzene). Fraction of $5 \%$ EtOAc/benzene $(100 \mathrm{ml})$ was evaporated to dryness. The residue was crystallized from $\mathrm{MeOH}$ as plates $(76 \mathrm{mg})$. The two crops were the same compound $(15,54 \%$ total yield) as evidenced by $\mathrm{mp}$ and IR; $\mathrm{mp} 165 \sim 166^{\circ} \mathrm{C}$. Anal. Found: C, 52.61; H, 5.30; S, 28.06. Calcd. for $\mathrm{C}_{10} \mathrm{H}_{12} \mathrm{O}_{2} \mathrm{~S}_{2}$ : C, $52.61 ; \mathrm{H}, 5.30 ; \mathrm{S}, 28.08 \%$.

2-Oxobicyclo[2.2.1] heptane-7-syn-carboxylic acid (8a). The dithioketal lactone $15(140 \mathrm{mg})$ was mixed with a freshly prepared Raney Ni suspension (W-4, $3 \mathrm{~g}$ of wet weight in $6 \mathrm{ml} \mathrm{EtOH}$ ). The mixture was refluxed for $30 \mathrm{~min}$ with stirring, and the catalyst was filtered off. The filtrate was concentrated by an evaporator, and the residual syrup (crude lactone 16; GC-MS $\left(t_{R}=21.1\right) \mathrm{m} / z: 138\left(\mathrm{M}^{+}\right)$) was dissolved in a mixture of $0.6 \mathrm{ml} \mathrm{MeOH}$ and $0.3 \mathrm{ml}$ of $6 \mathrm{~N}$ $\mathrm{NaOH}$. The solution was kept at $60^{\circ} \mathrm{C}$ for $1 \mathrm{hr}$ and then diluted with $1 \mathrm{ml}$ water. After acidification with $6 \mathrm{~N} \mathrm{HCl}$ and saturation with $\mathrm{NaCl}$, the aqueous solution was extracted with EtOAc $(7 \mathrm{ml} \times 3)$. The combined organic phase was washed with $1 \mathrm{ml}$ of saturated brine and then evaporated to dryness. The residue (crude syn hydroxy acid 7a; GC-MS for the methyl ester $\left(t_{R}=11.0\right) \mathrm{m} / \mathrm{z}: 170$ $\left(\mathrm{M}^{+}\right)$) was dissolved in $2 \mathrm{ml}$ acetone and mixed with $0.3 \mathrm{ml}$ of Jones reagent under cooling with ice. After $30 \mathrm{~min}, 0.6 \mathrm{ml}$ of isopropyl alcohol and $1 \mathrm{ml}$ water were added to the reaction mixture. The green solution was saturated with $\mathrm{NaCl}$ and then extracted with EtOAc $(5 \mathrm{ml} \times 3)$. The extracts were worked up in the usual way to give a syrup, which was purified by silica gel column chromatography (EtOAc/benzene). The product $( \pm)-\mathbf{8 a}$ was crystallized from benzene/hexane as leaflets $(48 \mathrm{mg}$, $51 \%$ yield), mp $117 \sim 119^{\circ} \mathrm{C}$ (lit. ${ }^{4)} \mathrm{mp} 122 \sim 123^{\circ} \mathrm{C}$ ). Anal. Found: $\mathrm{C}, 62.34 ; \mathrm{H}, 6.52$. Calcd. for $\mathrm{C}_{8} \mathrm{H}_{10} \mathrm{O}_{3}$ : C, 62.33; $\mathrm{H}, 6.54 \%$. IR $v_{\max }^{\mathrm{KBr}} \mathrm{cm}^{-1}: 2800 \sim 2300,1740(\mathrm{C}=\mathrm{O})$, and $1690(\mathrm{COOH})$. In the same way, $(1 R)-(+)-8 \mathrm{a}$ was synthesized from $(+)-14$ via dithioketal lactone $\left(\mathrm{mp} 157 \sim 158^{\circ} \mathrm{C}\right.$, $[\alpha]_{\mathrm{D}}^{31}+60.9^{\circ}(c=0.63, \mathrm{MeOH})$. Anal. Found: C, 52.57; $\mathrm{H}$, 5.28; S, 28.19. Calcd. for $\mathrm{C}_{10} \mathrm{H}_{12} \mathrm{O}_{2} \mathrm{~S}_{2}: \mathrm{C}, 52.61 ; \mathrm{H}, 5.30 ; \mathrm{S}$, $28.08^{\circ} \%$ ) in $41 \%$ yield as needles, $\mathrm{mp} 82 \sim 83^{\circ} \mathrm{C},[\alpha]_{\mathrm{D}}^{24}+9.8^{\circ}$ $(c=0.39, \mathrm{MeOH})$. Anal. Found: C, 62.20; H, 6.59. Calcd. for $\mathrm{C}_{8} \mathrm{H}_{10} \mathrm{O}_{3}: \mathrm{C}, 62.33 ; \mathrm{H}, 6.54 \%$. MS $m / z: 154\left(\mathrm{M}^{+}\right), 126$, $108,81,80,67$, and 66. IR $v_{\max }^{\mathrm{KBr}} \mathrm{cm}^{-1}: 3400,2970$, $2800 \sim 2300,1740(\mathrm{C}=\mathrm{O}), 1710(\mathrm{COOH}), 1420,1300$, $1220,1200,1150,1090$, and 710. PMR $\left(\mathrm{CDCl}_{3}\right) \delta: 1.57$ $(2 \mathrm{H}, \mathrm{m}), 1.83 \sim 2.05(3 \mathrm{H}$, complex m), $2.41(1 \mathrm{H}, \mathrm{m}), 2.80$ $(2 \mathrm{H}, \mathrm{m}), 2.92(1 \mathrm{H}, \mathrm{m})$, and $8.70(1 \mathrm{H}$, br.s, $\mathrm{COOH})$.

2-Endo-hydroxy- $\quad(\mathbf{6 b})$ and 2-exo-hydroxybicyclo[2.2.1] heptane-7-syn-carboxylic acid methyl ester (7b) were prepared as a mixture $(6 \mathbf{b}: 7 \mathbf{b}=4: 1)$ from both $( \pm)-\mathbf{8} \mathbf{a}$ and $(1 R)-(+)-8 \mathbf{a}$ in the same way as described for 5a. GC-MS $m / z$ : $170\left(\mathbf{M}^{+}\right)$for $6 \mathbf{b}\left(t_{R}=16.2\right)$ and $m / z$ : $170\left(\mathbf{M}^{+}\right)$for $7 \mathbf{b}\left(t_{R}=11.3\right)$.

2-Iodo-5-oxobicyclo[2.2.1]heptane-7-syn-carboxylic acid (17a) was synthesized from 12 by the method of Beeley $e t$ al.,$^{6)}$ in $76 \%$ yield, dec $204 \sim 205^{\circ} \mathrm{C}$ (lit. ${ }^{6)} \mathrm{mp} 227 \sim 228^{\circ} \mathrm{C}$ ),
MS $m / z: 280\left(\mathrm{M}^{+}\right)$. The acid 17a was methylated with ethereal diazomethane and the product $\mathbf{1 7 b}$ was crystallized from $\mathrm{EtOH}$ as rods $\left(90 \%\right.$ yield), $\mathrm{mp} 105 \sim 106^{\circ} \mathrm{C}$. Anal. Found: C, 36.59; H, 3.72; I, 43.33. Calcd. for $\mathrm{C}_{9} \mathrm{H}_{11} \mathrm{O}_{3} \mathrm{I}: \mathrm{C}, 36.76 ; \mathrm{H}, 3.77 ; \mathrm{I}, 43.15 \%$.

Iodo ketal ester (18). To a solution of $1.85 \mathrm{~g}$ of the iodo keto ester 17b in $14.5 \mathrm{ml}$ benzene were added $3.5 \mathrm{~g}$ of freshly prepared 2-methyl-2-ethyl-1,3-dioxolane ${ }^{22}$ and $0.27 \mathrm{~g}$ of tosic acid monohydrate. The mixture was stirred at room temperature overnight. Then, the mixture was diluted with $10 \mathrm{ml}$ benzene and successively washed with $10 \% \mathrm{NaHCO}_{3}(15$ and $5 \mathrm{ml})$. The organic phase was worked up in the usual way and the product 18 was crystallized from ether/pentane as leaflets $(1.93 \mathrm{~g}, 91 \%$ yield), mp $78 \sim 79^{\circ}$ C. Anal. Found: C, 38.93; H, 4.48; I, 37.59. Calcd. for $\mathrm{C}_{11} \mathrm{H}_{15} \mathrm{O}_{4} \mathrm{I}: \mathrm{C}, 39.07 ; \mathrm{H}, 4.47 ; \mathrm{I}, 37.53 \%$.

2-Oxobicyclo[2.2.1]hept-5-ene-7-anti-carboxylic acid (11a). The iodo ketal ester $18(1.2 \mathrm{~g})$ was dissolved in a mixture of $12 \mathrm{ml}$ toluene and $5.5 \mathrm{~g}$ of 1,8-diazabicyclo[5.4.0]undec-7-ene. The mixture was refluxed for $9 \mathrm{hr}$. After dilution with $50 \mathrm{ml}$ benzene, the reaction mixture was successively washed with $10 \%$ citric acid (50 and $10 \mathrm{ml})$ and saturated brine $(10$ and $5 \mathrm{ml})$. The organic phase was evaporated to dryness. The residue (crude unsaturated ketal ester 19 (GC-MS $\left(t_{R}=10.8\right.$, in GC condition 2, but column temperature $=160^{\circ} \mathrm{C}$ ) $\mathrm{m} / \mathrm{z}: 210$ $\left(\mathrm{M}^{+}\right)$) was mixed with $10 \mathrm{ml}$ of $30 \% \mathrm{AcOH} /$ water and heated to $95^{\circ} \mathrm{C}$ for $2 \mathrm{hr}$. The acetic acid and water were removed under vacuum as an azeotropic mixture with toluene and $\mathrm{EtOH}$, respectively. The residual liquid was chromatographed on a silica gel column $(2 \times 15 \mathrm{~cm})$, eluting with $200-\mathrm{ml}$ portions of $0 \sim 20 \%$ EtOAc/benzene mixtures. The eluate was divided into $20-\mathrm{ml}$ fractions, and monitored by TLC for the product. Fractions containing the pure product $(10 \%$ EtOAc/benzene) were combined and concentrated to give a syrup (unsaturated keto ester 11b, GC-MS $\left(t_{R}=13.0\right) \mathrm{m} / z$ : $\left.166\left(\mathrm{M}^{+}\right)\right)$, which was hydrolyzed in a mixture of $2 \mathrm{ml} \mathrm{MeOH}$ and $1 \mathrm{ml}$ of $6 \mathrm{~N}$ $\mathrm{NaOH}$ at $40^{\circ} \mathrm{C}$ for $30 \mathrm{~min}$. The solution was diluted with water $(3 \mathrm{ml})$, acidified with $6 \mathrm{~N} \mathrm{HCl}$, saturated with $\mathrm{NaCl}$, and extracted with EtOAc $(20 \mathrm{ml} \times 3)$. The extracts were worked up in the usual way and the product $( \pm)-11$ a was crystallized from benzene/hexane as leaflets $(0.36 \mathrm{~g}, 67 \%$ yield from 18), mp $126 \sim 127^{\circ} \mathrm{C}$ (lit. ${ }^{9)} \mathrm{mp} 120 \sim 122^{\circ} \mathrm{C}$ ). Anal. Found: C, 63.12; H, 5.30. Calcd. for $\mathrm{C}_{8} \mathrm{H}_{8} \mathrm{O}_{3}$ : C, $63.15 ; \mathrm{H}, 5.30 \%$. IR $v_{\max }^{\mathrm{KBr}} \mathrm{cm}^{-1}: 2600 \sim 2300,1730(\mathrm{C}=\mathrm{O})$, and $1700(\mathrm{COOH})$. PMR $\left(\mathrm{CDCl}_{3}\right) \delta: 6.13(1 \mathrm{H}, \mathrm{m})$ and $6.54(1 \mathrm{H}, \mathrm{m})$.

( 1R)-(-)-2-Oxobicyclo[2.2.1]hept-5-ene-7-anticarboxylic acid $((1 R)-(-)-11 a)$ was synthesized from (+)$12(0.25 \mathrm{~g})$ by the same sequential procedures already described. The intermediates $(17 \mathbf{a}, 17 \mathbf{b}$ and 18) were not crystallized in this case, but checked by TLC with reference to the corresponding racemic specimen ( $R f 0.49$, $0.55,0.35$ and 0.39 for $17 b, 18,19$ and $11 b$, respectively, on silica gel $\mathrm{F}_{254}$ developed with EtOAc/benzene (1:9)). The final product was crystallized from benzene/hexane as 
leaflets $(82 \mathrm{mg}, 33 \%$ yield $), \mathrm{mp} 152 \sim 153^{\circ} \mathrm{C},[\alpha]_{\mathrm{D}}^{25}-644^{\circ}$ $(c=0.30, \mathrm{MeOH})$. Anal. Found: C, 63.41; H, 5.29. Calcd. for $\mathrm{C}_{8} \mathrm{H}_{8} \mathrm{O}_{3}: \mathrm{C}, 63.15 ; \mathrm{H}, 5.30 \%$. MS $m / z: 152\left(\mathrm{M}^{+}\right), 124$, $110,82,79$, and 66. IR $v_{\max }^{\mathrm{KBr}} \mathrm{cm}^{-1}: 3420,3100,3020$, $2700 \sim 2300,1730(\mathrm{C}=\mathrm{O}), 1700(\mathrm{COOH}), 1410,1320$, $1250,1220,1120,1080,860,780,740$, and 700. PMR $\left(\mathrm{CDCl}_{3}\right) \delta: 2.09(2 \mathrm{H}, \mathrm{m}), 3.16(1 \mathrm{H}$, br.s $), 3.39(1 \mathrm{H}, \mathrm{m})$, $3.55(1 \mathrm{H}, \mathrm{m}), 6.13(1 \mathrm{H}, \mathrm{m}), 6.54(1 \mathrm{H}, \mathrm{m})$, and $8.50(1 \mathrm{H}$, br.s, $\mathrm{COOH})$.

2-Endo-hydroxy- (9b) and 2-exo-hydroxybicyclo[2.2.1]hept-5-ene-7-anti-carboxylic acid methyl ester (10b) were prepared as a mixture $(9 \mathbf{b}: \mathbf{1 0 b}=92: 8)$ from both ( \pm$)-11 \mathrm{a}$ and $(1 R)-(-)-11 \mathrm{a}$ in the same way as described for 5a. GC-MS $m / z: 168\left(\mathrm{M}^{+}\right)$for $9 \mathrm{~b}\left(t_{R}=11.8\right.$ in GC condition 3$)$ and $m / z: 168\left(\mathrm{M}^{+}\right)$for $10 \mathrm{~b}\left(t_{R}=14.0\right)$.

2-Exo-hydroxy esters $\mathbf{1 0 b}$ and $\mathbf{4 b}$ from 7methoxycarbonylbicyclo[2.2.1] hepta-2,5-diene (20). Bicyclo[2.2.1]hepta-2,5-diene-7-carboxylic acid (mp 79 $81^{\circ} \mathrm{C}$, MS $\mathrm{m} / \mathrm{z}$ : $136\left(\mathrm{M}^{+}\right)$; lit. $\left.^{23)} \mathrm{mp} 84.5 \sim 86^{\circ} \mathrm{C}\right)$ was synthesized by the carboxylation of 7-chloronorbornadiene according to Stapersma et al. ${ }^{23)}$ The acid was methylated with diazomethane. The diene ester 20 (100 mg) was dissolved under $\mathrm{N}_{2}$ in $1.4 \mathrm{ml}$ dry tetrahydrofuran containing $90 \mathrm{mg}$ 9-borabicyclo[3.3.1]nonane. After stirring at room temperature for $20 \mathrm{~min}, 0.32 \mathrm{ml}$ of $6 \mathrm{~N}$ $\mathrm{NaOH}$ and $0.30 \mathrm{ml}$ of $30 \% \mathrm{H}_{2} \mathrm{O}_{2}$ were added to the solution. The mixture was refluxed for $25 \mathrm{~min}$. Then, the reaction mixture was diluted with water $(3 \mathrm{ml})$, acidified with $6 \mathrm{~N} \mathrm{HCl}$, saturated with $\mathrm{NaCl}$, and extracted with ether $(7 \mathrm{ml} \times 3)$. The organic phases were combined and mixed with an excess amount of ethereal diazomethane. The mixture was allowed to stand at room temperature for several hours and then evaporated to dryness. The residue was purified by silica gel column chromatography (EtOAc/benzene) and finally $\mathbf{1 0 b}$ was obtained as a liquid ( $52 \mathrm{mg}, 46 \%$ yield), GC-MS $\left(t_{R}=14.2\right.$ in GC condition 3 ) $\mathrm{m} / z: 168\left(\mathrm{M}^{+}\right)$. This sample of $\mathbf{1 0 b}(25 \mathrm{mg})$ was dissolved in $1.5 \mathrm{ml} \mathrm{MeOH}$ and hydrogenated over $10 \% \mathrm{Pd} / \mathrm{C}(10 \mathrm{mg})$ at atmospheric pressure for $2 \mathrm{hr}$. The catalyst was filtered off. Concentration of the filtrate gave $\mathbf{4 b}$ as a liquid in an almost quantitative yield, GC-MS $\left(t_{R}=16.0\right) \mathrm{m} / \mathrm{z}: 170$ $\left(\mathrm{M}^{+}\right)$.

\section{Preparation of diastereomeric derivatives and $G C$}

Derivatives of the anti hydroxy esters $(\mathbf{3 b}+\mathbf{4 b})$. Two hundred and fifty milligrams of $\mathbf{5 a}$ were converted to a mixture of $\mathbf{3 b}$ and $\mathbf{4 b}$ in an analogous manner to that already described, but using $\mathrm{MeOH}$ as the solvent in the borohydride reduction. The product $(\mathbf{3 b}: \mathbf{4 b}=97: 3)$ was dissolved in $2.5 \mathrm{ml}$ toluene. An equal portion of the solution $(0.5 \mathrm{ml})$ was added to the following mixtures: (a) $3 \mathrm{ml}$ toluene containing $0.3 \mathrm{mmol} 21$ and $100 \mu \mathrm{l}$ pyridine; (b) $3 \mathrm{ml} \mathrm{CHCl}{ }_{3}$ containing $0.3 \mathrm{mmol} 22$ and $100 \mu \mathrm{l}$ pyridine; (c) $0.5 \mathrm{ml}$ toluene containing an acid chloride freshly prepared from $200 \mathrm{mg} 23$ and $100 \mu 1$ pyridine; (d) $0.5 \mathrm{ml}$ toluene containing $200 \mathrm{mg} 26$ and $100 \mu \mathrm{l}$ pyridine; (e) $10 \mathrm{mg} N, N$-dimethylethanolamine and $100 \mu \mathrm{l} \mathrm{24}$. The mixtures of (c) and (d) were heated to $60^{\circ} \mathrm{C}$ for $1 \mathrm{hr}$, and the mixtures of (b) and (e) were heated to $90^{\circ} \mathrm{C}$ for 0.5 and $14 \mathrm{hr}$, respectively. The mixture of (a) was heated to $90^{\circ} \mathrm{C}$ for $0.5 \mathrm{hr}$ and then stirred at room temperature overnight. Each mixture was diluted with EtOAc $(15 \mathrm{ml})$ and successively washed with $5 \mathrm{ml}$ of water, $5 \% \mathrm{NaHCO}_{3}, 10 \%$ citric acid, and saturated brine. The EtOAc layers were dried over $\mathrm{Na}_{2} \mathrm{SO}_{4}$, concentrated to approximately $1 \mathrm{ml}$, and subjected to GC. Derivatives of the syn hydroxy esters $(\mathbf{6 b}+\mathbf{7 b})$ with $\mathbf{2 6}$ were similarly prepared, but in a small scale and without the washing procedures.

Derivatives with the isocyanate 27. An EtOAc solution containing about $0.5 \mathrm{mg}$ of the sample (one of the racemic and/or enantiomerically pure specimens of $\mathbf{3 b}+\mathbf{4 b}, \mathbf{4 b}$, $\mathbf{6 b}+7 \mathbf{b}, 7 \mathbf{b}, 9 \mathbf{b}+\mathbf{1 0 b}$, and 10b) was placed in an ampoule and the solvent was removed under vacuum. To the residue was added a mixture of $17.8 \mu \mathrm{l}$ toluene, $0.2 \mu \mathrm{l} \mathrm{N}, \mathrm{N}$ dimethylethanolamine (as a catalyst), ${ }^{24)}$ and $2 \mu \mathrm{l} \mathrm{27}$. The ampoule was sealed and heated to $95^{\circ} \mathrm{C}$ for $12 \mathrm{hr}$. The reaction mixture was diluted with $30 \sim 100 \mu 1 \mathrm{MeOH}$ before GC analysis. The reaction rate was more than $95 \%$ in the case of $\mathbf{3 b}+\mathbf{4 b}$ as evidenced by GC for the unreacted substrates.

Derivatives of the keto acids. A portion of $( \pm)-5 a$ (about $0.5 \mathrm{mg}$ ) was mixed with $50 \mu \mathrm{l}$ thionyl chloride. The mixture was allowed to stand at room temperature for $1 \mathrm{hr}$. The excess thionyl chloride was removed under vacuum, and a trace amount of the reagent was purged with toluene. The residue was mixed with $20 \mu \mathrm{l}$ toluene, $2 \mu \mathrm{l}$ pyridine and $1 \mu \mathrm{l}$ 25, and kept at room temperature for over $1 \mathrm{hr}$. This sample was adequately diluted with $\mathrm{MeOH}$ before GC. A similar procedure was repeated, but using $(+)-5 \mathbf{a}$ and $(-)-5 \mathbf{a},( \pm)-8 \mathbf{a}$ and $(+)-8 \mathbf{a}$, and $( \pm)-11 \mathbf{a}$ and $(-)-11 \mathbf{a}$. Also a reaction was carried out with $5 \mathrm{a}$ and $2 \mu \mathrm{l} 28$ instead of $\mathbf{2 5}$. The reaction rate in the case of $\mathbf{5 a}$ with $\mathbf{2 5}$ was more than $80 \%$ in the above coupling condition, as evidenced by GC for the remaining 5a (after methylation with diazomethane).

$G C$ on $O V-1701$ and $B P-20$ for the derivatives of $\mathbf{3 b}+\mathbf{4 b}$ (a) and $\mathbf{6 b}+\mathbf{7 b}(b)$ with $\mathbf{2 6}$. Retention times (min) on OV1701 capillary column: a-42.20, 44.13, 49.25 and 50.42; b $-34.78,36.25,44.54$ and 45.60 ; conditions: inlet pressure, $1.25 \mathrm{~kg} / \mathrm{cm}^{2}$; carrier flow rate at inlet, $70 \mathrm{ml} / \mathrm{min}$; column temperature, $220^{\circ} \mathrm{C}$; and flow rate in column, $0.83 \mathrm{ml} / \mathrm{min}$. Retention times $(\mathrm{min})$ on BP-20 capillary column: $\mathrm{a}-28.98,30.90,35.52$ and $37.14 ; \mathrm{b}-22.20,23.70$, 30.60 and 32.04; conditions: inlet pressure, $1.8 \mathrm{~kg} / \mathrm{cm}^{2}$; carrier flow rate at inlet, $70 \mathrm{ml} / \mathrm{min}$; column temperature, $200^{\circ} \mathrm{C}$; and flow rate in column, $1.0 \mathrm{ml} / \mathrm{min}$.

$G C$ for the derivatives of $\mathbf{6 b}+7 \mathbf{b}$ with 27 on $O V-1$. The same conditions as those in Fig. If were used. Retention times ( $\mathrm{min}$ ): $33.28,35.33,40.68$ and 41.20 (37.74, 38.89, 44.39 and 45.36 for the peaks in Fig. 1f).

$G C$ for the diastereomeric urethanes of the hydroxy esters with 27 on the 50-m OV-1 capillary column. Chromatographic conditions were the same as those in Fig. 2. Retention time (min) and assignment (as hydroxy ester): 
51.35, (1 $S)-\mathbf{4 b} ; 52.68,(1 R)-4 \mathbf{b} ; 59.22,(1 R)-3 \mathbf{b} ; 60.30,(1 S)-$ 3b; 47.79, (1 $S)-7 \mathbf{b} ; 50.13,(1 R)-7 \mathbf{b} ; 56.13,(1 R)-6 \mathbf{b} ; 56.79$, $(1 S)-\mathbf{6 b} ; 45.90,(1 S)-10 \mathbf{b} ; 47.07,(1 R)-10 b ; 53.49,(1 R)-9 b ;$ $54.32,(1 S)-9 b$.

$G C$ for the diastereomeric amides of the keto acids with 25. Conditions: OV-1 capillary $(25 \mathrm{~m})$; inlet pressure and carrier flow rate, $1.25 \mathrm{~kg} / \mathrm{cm}^{2}$ and $75 \mathrm{ml} / \mathrm{min}$; column temperature and flow rate in column, $180^{\circ} \mathrm{C}$ and $1.0 \mathrm{ml} / \mathrm{min}$. Retention time ( $\mathrm{min}$ ) and assignment (as keto acid): 28.54, (1 $R)-5 \mathbf{a} ; 29.46,(1 S)-5 \mathbf{a} ; 30.60,(1 S)-8 \mathbf{a} ; 32.52$, (1 R)-8a; 25.15, (1 R)-11a; 26.13, (1 S)-11a.

\section{REFERENCES}

1) Y. Yamazaki and H. Maeda, Agric. Biol. Chem., 49, 3203 (1985).

2) (a) W. H. Pirkle and S. D. Beare, J. Am. Chem. Soc., 91, 5150 (1969); (b) G. M. Whitesides and D. W. Lewis, J. Am. Chem. Soc., 92, 6979 (1970); (c) T. Oishi and H. Akita, Yuki Gosei Kagaku Kyokaishi, 41; 1031 (1983).

3) (a) C. H. Lochmüller and R. W. Souter, J. Chromatogr., 113, 283 (1975); (b) I. S. Krull, "Advances in Chromatography," Vol. 16, ed. by J. C. Giddings, E. Grushka, J. Cazes and P. R. Brown, Marcel Dekker, Inc., New York, 1980, p. 175; (c) E. Gil-Av and D. Nurok, "Advances in Chromatography," Vol. 10, ed. by J. C. Giddings and R. A. Keller, Marcel Dekker, Inc., New York, 1974, p. 99.

4) P. Flury and C. A. Grob, Helv. Chim. Acta, 66, 1981, 1991 (1983).

5) S. Torii, H. Tanaka and T. Mandai, J. Org. Chem., 40, 2221 (1975).

6) N. R. A. Beeley, R. Peel, J. K. Sutherland, J. J. Holohan, K. B. Mallion and G. J. Sependa, Tetrahedron, 37, Suppl. No. 1, 411 (1981).
7) F. M. Menger and L. E. Glass, J. Am. Chem. Soc., 102, 5404 (1980).

8) (a) M. Nakazaki, K. Naemura and H. Kadowaki, J. Org. Chem., 43, 4947 (1978); (b) M. Nakazaki, K. Naemura and H. Kadowaki, J. Org. Chem., 41, 3725 (1976).

9) J. S. Bindra, A. Grodski, T. K. Schaaf and E. J. Corey, J. Am. Chem. Soc., 95, 7522 (1973).

10) H. C. Brown and J. Muzzio, J. Am. Chem. Soc., 88, 2811 (1966).

11) W. C. Baird, Jr. and J. H. Surridge, J. Org. Chem., 37, 304 (1972).

12) M. Hamberg, Anal. Biochem., 43, 515 (1971).

13) A. B. Attygalle and E. D. Morgan, J. Chromatogr., 260, 411 (1983).

14) R. E. Doolittle and R. R. Heath, J. Org. Chem., 49, 5041 (1984).

15) W. Pereira, V. A. Bacon, W. Patton, B. Halpern and G. E. Pollock, Anal. Lett., 3, 23 (1970).

16) C. J. W. Brooks, M. T. Gilbert and J. D. Gilbert, Anal. Chem., 45, 896 (1973).

17) A. Murano and S. Fujiwara, Agric. Biol. Chem., 37, 1977 (1973).

18) K. D. Ballard, T. D. Eller and D. R. Knapp, J. Chromatogr., 275, 161 (1983).

19) C. J. W. Brooks and J. D. Gilbert, J. Chem. Soc., Chem. Commun., 194 (1973).

20) J. Casanova, Jr. and E. J. Corey, Chem. Ind., 1664 (1961).

21) P. A. Grieco, W. Owens, C.-L. J. Wang, E. Williams, W. J. Schillinger, K. Hirotsu and J. Clardy, J. Med. Chem., 23, 1072 (1980).

22) H. J. Dauben, Jr., B. Löken and H. J. Ringold, $J$. Am. Chem. Soc., 76,.1359 (1954).

23) J. Stapersma and G. W. Klumpp, Tetrahedron, 37, 187 (1981).

24) W. H. Pirkle and M. S. Hoekstra, J. Org. Chem., 39, 3904 (1974). 